\title{
NOVI KONCEPT UPRAVLJAČKOG RAČUNOVODSTVA ZA MIKRO, MALA I SREDNJA PREDUZEĆA ${ }^{1}$
}

\author{
Dragutin Dragojević ${ }^{1}$, Tatjana Miljević ${ }^{2}$ \\ ${ }^{1}$ Evropski centar za mir i razvoj (ECPD), Terazije 41, Beograd, Srbija \\ ${ }^{2}$ TMS CEE doo, Rudnička 2, Beograd, Srbija
}

\begin{abstract}
Apstrakt:
Nakon izbijanja svetske ekonomske krize 2008. godine, rukovodstvo mikro, malih i srednjih preduzeća (MMSP) raspolaže sa sve manje adekvatnih upravljačkih alata i pouzdanih informacija koje su neophodne za pripremu i donošenje ispravnih menadžerskih odluka, a sve u cilju ostvarenja željenih poslovnih ciljeva, finansijske stabilnost i dugoročne sigurnosti. Literatura iz oblasti upravljačkog računovodstva uglavnom obuhvata namenska rešenja koja zadovoljavaju potrebe velikih korporacija i njihovog menadžmenta. Menadžment u mikro, malim i srednjim preduzećima ima malo toga zajedničkog sa organizacijama kao i sa načinom funkcionisanja upravljačkog računovodstva namenjenog velikim korporacijama. Ovim preduzećima su potrebne informacije koje se ne mogu pronaći u stručnoj literaturi. U ovom radu pažnja je usmerena na razvoj i primenu novih koncepata i alata upravljačkog računovodstva koji bi odgovarali potrebama menadžmenta mikro, malih i srednjih preduzeća. Literatura i računovodstvena teorija dugo su ignorisali potrebu za upravljačkim računovodstvom mikro, malih i srednjih preduzeća, što je postao ograničavajući faktor u njihovom razvoju. Ovaj rad daje uvid u neke od ključnih upravljačkih finansijskih informacija, uključujući efikasan poslovni plan, procenu mobilnosti tržišta, predviđeni obim proizvodnje, finansijske izvore neophodne za budžetiranje, fiksne i varijabilne troškove, definisanje profitabilnosti za celokupne operacije u okviru MMSP, projekcije novčanih tokova. U radu se navode primeri koji su prethodno potvrđeni u praksi.
\end{abstract}

\author{
Ključne reči: \\ specifično upravljačko \\ računovodstvo, \\ upravljačke kontrole, \\ veličina firme, \\ MMSP (mikro, mala i srednja \\ preduzeća).
}

\section{UVOD}

U ovom radu, pažnja je usmerena na istraživanja do sada primenjivanog koncepta o upravljačkom računovodstvu, koja su namenjena prvenstveno korporativnom menadžmentu $\mathrm{u}$ velikim multinacionalnim i nacionalnim korporacijama. Razvoj malih i srednjih preduzeća u savremenim uslovima konsolidacije globalne ekonomije u cilju bržeg izlaska iz nastale globalne finansijske krize 2008. godine, koja još traje, predstavlja ključni faktor budućeg ekonomskog razvoja. Specifičnosti i posebne potrebe upravljačkog računovodstva za mala i srednja preduzeća dugo su ignorisane. Tek u poslednjih 10 godina javljaju se intenzivnija istraživanja specifičnosti malih i srednjih preduzeća i kreiranje novog koncepta upravljačkog računovodstva u skladu sa njihovim aktuelnim potrebama. Međutim, ukorenjenost korporativnog upravljačkog računovodstva uticala je na pretežno fragmentarno prilagođavanje potrebama menadžmenta malih i srednjih preduzeća, prvenstveno za kontrolu troškova, kontrolu kalkulacija prodajnih cena, kontrolu inventarisanja svih oblika zaliha, a manje o svim

1 Ovaj istraživački projekat pripremljen je za CFRR - Centar za reformu finansijskog izveštavanja World Bank Group drugim ključnim aspektima upravljčakog računovodstva koji su neophodni za efikasnije upravljanje mikro, malim i srednjim preduzećima u otežanim uslovima poslovanja.

Za sada nije potpuno jasno šta sve urgentno treba da obuhvati specifično upravljačko računovodstvo malih i srednjih preduzeća. Potencijalni razlozi mogu se pronaći u vrlo rasprostranjenim sadržajima objavljenim u okviru različitih oblasti računovodstva, malog biznisa, i preduzetništva, opštim načelima modernog upravljanja ili operacijama upravljanja proizvodnjom i poslovanjem. U postojećim poznatim časopisima o upravljačkom računovodstvu, kao što je Journal of Management Accounting Research, koji izdaje The American Accounting Association - AAA, kao i u drugim poznatim časopisima uglavnom se publikuju teme o upravljačkom računovodstvu koje su dizajnirane prema potrebama velikih korporacija.

Radi podsticaja bržeg prevazilaženja postojećeg stanja, nedostatka dovoljnog broja istraživačkih radova i tema iz upravljačkog računovodstva, prilagođeno potrebama vlasnika mikro, malih i srednjih preduzeća Lopez \& Hiebl (2015) sumiraju postojeću literaturu o upravljačkom računovodstvu za mala i srednja preduzeća. Na globalnom nivou, oni 
ukazuju na pravce budućih istraživanja razvoja specifičnog upravljačkog računovodstva prilagođenog za mikro, mala i srednja preduzeća u budućnosti, kako bi se podržali napori na poboljšanju kvaliteta upravljanja, koja su najbrojnija u praksi. Napredak u razvoju mikro, malih i srednjih preduzeća treba da pokrene brzi privredni rast, otvaranje novih radnih mesta i brzou finansijsku konsolidaciju mnogih zemalja u svetu koja su zapala u duboke finansijske teškoće.

\section{SPECIFIČNI ZAHTEVI UPRAVLJAČKOG RAČUNOVODSTVA ZA MIKRO, MALA I SREDNJA PREDUZEĆA}

Mala i srednja preduzeća zahtevaju posebnu pažnju koja dolazi od upravljačkog računovodstva zato što ona imaju posebne resurse i susreću se sa posebnim teškoćama u odnosu na velike korporacije. Mikro, mala i srednja preduzeća obično imaju limitiran pristup resursima i manje mogućnosti za pristup novim naprednijim ekonomskim resursima. U odnosu na velike korporacije krucijalno pitanje za mikro, mala i srednja preduzeća uspešno upravljanje njihovim izvorima sredstava, odnosno resursima koristeći prave informacije i kontrolu sistema.

Sistem upravljačkog računovodstva može podržati mala i srednja preduzeća za vođenje uspešnog poslovanja, korišćenjem upravljačkih informacija koje su potrebne menadžmentu svake organizacije (Kaplan \& Atkinson, 2011). Takođe, upravljačko računovodstvo u mikro, malim i srednjim preduzećima doprinosi značajnom uključivanju i nekih ključnih korporativnih funkcija za bolje podržavanje njihovih poslovnih funkcija, naročito u obezbeđenju informacija koje su izuzetno važne za uspešno upravljanje raspoloživim resursima, adekvatno planiranje i kontrolu poslovanja.

Ograničeni resursi u malim i srednjim preduzećima često onemogućuju specijalizaciju upravljačkog računovodstva, odnosno stalno vođenje posebnih računa, npr. za planiranje i kontrolu troškova. Nedostatak resursa u malim i srednjim preduzećima, često se delimično ili potpuno reflektuje na nedostatke u upravljanju i neposedovanju odgovarajućih računovodstvenih znanja i veština, uključujući i nemogućnost adekvatnog treninga osoblja u malim i srednjim preduzećima; odsustvo neophodnog treninga vlasnike i preduzetnika za bolje razumevanje primene i koristi finansijskog računovodstva; kao i organizovanje specijalizovanog upravljačkog računovodstva, kao važnog alata uspešnog upravljanja raspoloživim resursima i poslovanja entiteta u celini.

\section{UTICAJ RAČUNOVODSTVENIH TEHNIKA NA POZICIONIRANJE UPRAVLJAČKOG RAČUNOVODSTVA}

Računovodstvene tehnike se često pojednostavljuju i adaptiraju potrebama mikro, malih i srednjih preduzeća. Pojednostavljenje i smanjenje sistema upravljačkog računovodstva koje je bilo projektovano za primenu u velikim korporacijama postaje nepodesno za primenu u malim i srednjim preduzećima. Brojni autori upravljačkog računovodstva ukazuju na činjenicu da "mali biznis nije mali-veliki biznis", što znači da je i malim i srednjim preduzećima potreban upravljački pristup prilagođen njihovim resursima. To se može najbolje videti upoređujući pozicioniranje upravljačkog računovodstva u velikim korporacijama.
Primena upravljačkog računovodstva u mikro, malim i srednjim preduzećima nije samo manje česta, već je takođe i različita. Stafler i Hance (2011), ističu da akademska istraživanja upravljačkog računovodstva pružaju praktičarima u mikro, malim i srednjim preduzećima značajnu stručnu pomoć upravo u boljem pozicioniranju primenjenog računovodstva za obezbeđenje potrebnih informacija vlasnicima i menadžerima radi unapređenja performansi, a samim tim i ukupnog poslovanja mikro, malih i srednjih preduzeća u praksi. U isto vreme takva praksa štedi izvore resursa malih i srednjih preduzeća fokusirajući se samo na najprikladnije tehnike upravljačkog računovodstva koje odgovaraju mogućnostima i upravljačkim zahtevima vlasnika mikro, malih i srednjih preduzeća. Pritom se izbegavaju ona pozicioniranja koja se isključivo oslanjaju na računovodstvene tehnike koje su projektovane, poznate i tradicionalno se primenjuju u velikim korporacijama.

U vezi sa navedenim, mikro, mala i srednja preduzeća imaju drugačija očekivanja od istraživanja mogućnosti detektovanja ili primene inovacionih tehnika u upravljačkom računovodstvu. Očekuje se kreiranje praktičnih sugestija navedenih zahteva prakse za boljim pozicioniranjem specifičnog upravljačkog računovodstva, u smislu adekvatnog pozicioniranja novih računovodstvenih tehnika prilagođenih potrebama specifičnog upravljačkog računovodstva za MMSP.

Nepostojanje adekvatnog upravljačkog računovodstva prilagođeno potrebama mikro, malih i srednjih preduzeća, onemogućuje vlasnicima, preduzetnicima ili angažovanim menadžerima regularno dobijanje neophodnih informacija o ostvarenim performansama poslovanja, čime je otežano upravljanje raspoloživim resursima, naročito efikasno upravljanje gotovinom, upravljanje i kontrola svih oblika zalihama, održavanje dobrih poslovnih odnosa sa klijentima (npr. informacije o reklamacijama, kretanju i kontroli održavanja fiksnih troškova, upoređenje ostvarenih performansi sa performansama konkurencije itd.).

\section{KARAKTERISTIKE KOJE UTIČU NA UPRAVLJAČKO RAČUNOVODSTVO U MALIM I SREDNJIM PREDUZEĆIMA}

Lopez i Hiebl (2015), su se posebno posvetili istraživanjima razvoja mikro, malih i srednjih preduzeća, na prvom mestu oni u fokus stavljaju njihove organizacione aspekte. Zapažen je značajni familijarni uticaji na organizacionu strukturu tih preduzeća, čime se utiče na definisanje pristupa u razvoju specifičnosti upravljačkog računovodstva (primer u Srbiji Delta holding, Farmakom MB, u Hrvatskoj Agrokor i brojni familijarni poslovni konglomerati u zemljama iz okruženja). U ostvarivanju adekvatne kontrolne funkcije slabi uloga specifičnog upravljačkog računovodstva, što je osnovni cilj njenog uvođenja i primene, jer su glavni menadžeri $(C E O)$ na čelu takvih preduzeća najčešće neprofesionalni članovi porodica. Zbog donošenja neposlovnih odluka, poslovno posrtanje ovih preduzeća je brzo, jer donosioci odluka najčešće ne razumeju specifično upravljačko računovodstvo, pa nisu u stanju da koriste važne upravljačke informacije ili koriste zastarele i neupotrebljive važne finansijske informacije prilikom donošenja svojih ključnih, strateških i operativnih poslovnih odluka.

Organizacioni i upravljački aspekti se bitno razlikuju po pojedinim grupama, kao što su mikro, mala ili srednja preduzeća. Svaka grupa ovih preduzeća ima različite potrebe za 
određenim upravljačkim informacijama, pa se i upravljačka računovodstva u takvim situacijama prilagođavaju tim zahtevima i potrebama.

Ključne razlike koje se javljaju u specifičnom upravljačkom računovodstvu za mikro, mala i srednja preduzeća mogu se grupisati prema sledećim kriterijumima:

a) specifično upravljačko računovodstvo, na prvom mestu, definiše se prema veličini organizacije,

b) specifično upravljačko računovodstvo se razvija prema zahtevima i potrebama okruženja organizacije,

c) specifično upravljačko računovodstvo se usklađuje sa sektorskim potrebama organizacije kojoj pripada,

d) specifično upravljačko računovodstvo se takođe usklađuje sa organizacionim aspektima same organizacije i na kraju,

e) novo specifično upravljačko računovodstvo se prilagođava savremenim računovodstvenim tehnologijama koje odgovaraju zahtevima i potrebama u mikro, malim i srednjim preduzećima.

U svakom slučaju, specifično upravljačko računovodstvo bi trebalo da ima kontrolnu funkciju, koja permanentno obezbeđuje informacije o ostvarenim poslovnim performansama, uključujući projektovanje i praćenje izvršenja budžeta bilo kog oblika ovih organizacija.

\section{PRILAGOĐAVANJE RAZVOJA SPECIFIČNOG UPRAVLJAČKOG RAČUNOVODSTVA VELIČINI MMSP}

Jedan od ključnih faktora u definisanju i prihvatanju novog koncepta specifičnog upravljačkog računovodstva zavisiće od veličine MMSP, pa sami tim i od obima potreba i kontinuiteta za određenom količinom upravljačkih informacija. U nekim slučajevima, zahtevani obim upravljačkih informacija opredeliće neke vlasnike, preduzetnike i menadžere u MMSP da više koriste uspešno primenjivana iskustva organizovanja upravljačkog računovodstva u velikim korporacijama.

Poznate su značajne razlike upravljačkog računovodstva u velikim korporacijama i mikro, malim i srednjim preduzećima. Dominantan je uticaj kontrolne funkcije i merenje ostvarenih performansi menadžmenta po nivoima odgovornosti koje se ostvaruju pomoću upravljačkog računovodstva u velikim korporacijama.

Veličina organizacije u mikro, malim i srednjim preduzećima utiče prvenstveno na strukturu potrebnih upravljačkih informacija prilikom dizajniranja koncepta specifičnog upravljačkog računovodstva. U mikro preduzeću, za vlasnika ili preduzetnika je od posebne važnosti praćenje ostvarenog prihoda i marginalne dobiti ili marže, na osnovu čega se prati stepen iskorišćenja raspoloživih resursa i obezbeđenja finansijskih sredstava za izvršavanje dospelih finansijskih obaveza prema bankama i poslovnim partnerima, kako finansijska podrška ne bi bila uskraćena.

Veličina proizvodnih i materijalno robnih preduzeća se takođe značajno razlikuje u organizacijama specifičnog upravljačkog računovodstva za potrebe uslužnih i nematerijalnih preduzeća. Materijalno i robno poslovanje zahteva posebnu razradu kontrole svih oblika zaliha, strukturu kalkulacija troškova i slično, dok je u uslužnim organizacijama dominantna kontrola ljudskih resursa, gde spada kontrola izostanaka sa posla, uticaj radnih uslova na pojavu bolovanja, formiranje skladnih radnih timova koji ostvaruju najbolje efekte rada i poslovanja.
Uticaj veličine organizacije je vrlo značajan, kod većeg ili manjeg obima novih investiranja, u primeni novih tehnologija, uvođenju modernije i bolje opreme ili uvođenju novih automatskih uređaja i postrojenja čime se doprinosi većoj produktivnosti rada, poboljšanju kvaliteta proizvoda i usluga, ostvarivanju efikasnijeg poslovanja, što doprinosi značajnom povećanju prihoda sa istim brojem zaposlenih, jačanju poslovne i tržišne pozicije i dugoročne izvesnosti ili sigurnosti poslovanja.

\section{FAKTORI KOJI UTIČU NA PROMENE ODNOSA PREMA UPRAVLJAČKOM RAČUNOVODSTVU U MMSP}

Posle nastanka globalne finansijske krize 2008 godine u praksi su posebno ističu neki faktori koji utiču na promene odnosa vlasnika, preduzetnika i njihovih angažovanih menadžera prema upravljačkom računovodstvu u mikro, malim i srednjim preduzećima i to:

- Promene pri povećanju veličine organizacije. Kada dođe do promene veličine organizacije, proširivanjem programa poslovanja, proširivanjem tržišta, povećanjem obima poslovanja, povećanjem broja zaposlenih, dokapitalizacijom i uopšte povećanjem resursa, sa dužim vekom postojanja MMSP javlja se potreba za promenom odnosa prema specifičnom upravljačkom računovodstvu. Zahtevi prema specifičnom upravljačkom računovodstvu, u tom slučaju, približavaju se strukturi i sadržaju upravljačkog računovodstva velikih korporacija, čime se podiže kvalitet $i$ upotrebna vrednost dobijenih informacija iz specifičnog upravljačkog računovodstva organizovanog za efikasnije upravljanje u mikro, malim i srednjim preduzećima. Ti događaji nastaju kada mikro preduzeće preraste u malo ili čak srednje preduzeće, najčešće kada malo preduzeće vremenom preraste u srednje preduzeće. Postoje slučajevi da i srednja preduzeća prerastu u velika preduzeća.

- Promene pri smanjenju veličine organizacije. Sa nastankom globalne ekonomske krize, smanjenjem kupovne snage stanovništva u mnogim mikro, malim o srednjim preduzećima dolazi do smanjenja potražnje za njihovim proizvodima i uslugama, pa samim tim i do smanjenja obima poslovanja, što utiče na smanjenje proizvodnje i poslovanja, smanjenje broja zaposlenih i dovodi do potrebe za novim upravljačkim informacijama. Smanjuje se obim upravljačkih informacija, sa jedne strane, i uvode promene manjeg obima upravljačkih informacija sa druge strane. Pažnja se usmerava na neutralisanje povećanih finansijskih rizika zbog otežane naplate potraživanja, otpisivanja nenaplativih potraživanja, reprogramiranja dospelih obaveza i nastojanja da se održi aktivan status organizacije i izbegne stečaj i bankrotstvo firme.

- Održavanje konkurentnosti poslovanja i poslovnog renomea firme. Postojanje velikog broja MMSP na otvorenom tržištu podstiče oštru konkurenciju između njih. Za održavanje konkurentnosti i pozicije na tržištu potrebne su dodatne informacije iz specifičnog upravljačkog računovodstva, kako bi se odgovarajuće upravljačke odluke mogle blagovremeno doneti, naročito u praćenju i smanjenju fiksnih troškova poslovanja i nabavkama pod povoljnijim varijabilnim 
troškovima organizaciji se otvara prostor za sniženje prodajnih cena ili davanje povoljnijih uslova prodaje, čime se povećava konkurentna pozicija organizacije na tržištu. Održavanje konkurentnosti organizacije je moguće samo pozitivnim odnosom vlasnika i menadžera organizovanju za unapređenje i proširenje zahteva u vođenju specifičnog upravljačkog računovodstva kako bi se obezbedile dodatne informacije za projektovanje i održavanje konkurentne sposobnosti organizacije u izmenjenim uslovima poslovanja.

- Faktori koji utiču na smanjenje uloge i primene upravljačkog računovodstva u MMSP. Postojanje mikro, malih i srednjih preduzeća u nerazvijenim područjima ili nerazvijenom poslovnom okruženju, sa niskim nivoom kulture poslovanja, nerazvijenom kulturom štednje i razvoja za budućnost utiču kao limitirajući faktori na razvoj, naročito u sagledavanju značaja i potrebe primene specifičnog upravljačkog računovodstva. Pre svega, u ovakvom poslovnom okruženju prisutno je nedovoljno obrazovanje vlasnika i menadžera za primenom modernog alata savremenog upravljanja, kao što je upravljačko računovodstvo, radi efikasnije zaštite od svih oblika tržišnih, investicionih i finansijskih rizika u poslovanju. U ovim sredinama zbog nepoznavanja upravljačkih veština, vlasnici i njihovi menadžeri u MMSP često se lako "kockaju” sa raspoloživim resursima i brzo dolaze u brojne poslovne teškoće koje ih brzo dovode do stečaja i bankrotstva. Nedovoljno posvećivanje pažnje ekološkoj zaštiti može da ugrozi prirodnu osnovu dugoročnog uspešnog poslovanja mikro, malih i srednjih preduzeća $u$ ovim sredinama.

- Faktori koji povećavaju primenu specifičnog upravljačkog računovodstva u MMSP. Naročito se ispoljava potreba za razvoj i povećanje primene upravljačkog računovodstva u mikro, malim i srednjim preduzećima kada dolazi do razdvajanja funkcija vlasnika i angažovanog menadžera u pogledu preciziranja računovodstvene odgovornosti menadžera za upravljanje poverenim resursima od strane vlasnika i ostvarivanje projektovanih poslovnih rezultata organizacije (ostvarivanje minimalnog okvira neto dobitka u poverenom poslovanju). U ovom slučaju, ne formira se CEO funkcija organizacije. Zbog toga su u ovom slučaju obe strane (vlasnik i ovlašćeni menadžer) zainteresovane za razvoj specifičnog upravljačkog računovodstva, koje se u znatnoj meri približava profilu upravljačkog računovodstva, koje je vrlo blisko upravljačkom računovodstvu u velikim korporacijama. Obe strane žele da im specifično upravljačko računovodstvo obezbedi odgovarajuće informacije o ostvarenim performansama poslovanja, radi stimulativnog nagrađivanja menadžera, s jedne strane i bolje zaštite vlasničkog kapitala, a naročito objektivnog praćenja i proveravanja ostvarivanja ugovorenog kapital prinosa, s druge strane (primer ugovorne obaveze menadžmenta za upravljanje Železarom Smederevo).

- Faktori koji smanjuju primenu specifičnog upravljačkog računovodstva u MMSP. Na prvom mestu je nedostatak treninga vlasnika i menadžera za ovladavanje potrebnim znanjima i veštinama modernog upravljanja uz ažurnu primenu upravljačkog računo- vodstva, kao osnovnog “alata” sa sigurno detektovanja ostvarivanja planiranog poslovanja, uticaja spoljnjeg okruženja i blagovremeno donošenje "odbrambenih" upravljačkih odluka (praćenje kritične tačke rentabilitet poslovanja, izbor povoljnijih snabdevača sirovina i usluga, brzo otkrivanje proizvoda i usluga gde je došlo do nepovoljne marže - marginalne dobiti i njihovo brzo zaustavljanje i isključivanje iz poslovnih planova i proizvodnje). Drugi ključni nepovoljan faktor je postojanje nefunkcionalne i neracionalne organizacije poslovanja, što uslovljava potrebu vlasnika da brzo pronalaženje sposobnog konsultanta koji će pomoći da u kratkom roku rehabilituje unutrašnju organizaciju poslovanja i na taj način shvatiti potrebu brzog uvođenja i primene specifičnog upravljačkog računovodstva za novi stil upravljanja i poslovanja. Treći ograničavajući faktor koji povećava nezainteresovanost za primenu upravljačkog računovodstva u MMSP je prisustvo neobučenog osoblja za primenu modernih finansijskih i računovodstvenih tehnologija, međunarodnih računovodstvenih standarda i sličnih "alata” za praćenje i merenje ostvarenih performansi poslovanja, naročito rentabilnosti poslovanja.

- Drugi faktori koji povećavaju interes za primenu upravljačkog računovodstva u MMSP. Veći interes za primenu specifičnog upravljačkog računovodstva naročito se javlja u kriznim uslovima poslovanja, gde je stvoren prostor za uvođenje efektnije interne kontrole rentabilnosti poslovanja, kao i za jačanje autoriteta i sigurnosti finansiranja zajedničkih poslovnih poduhvata (Joint Venture), naročito u realizaciji većih projekata ili poslovnih poduhvata, gde je neophodno udruživanje finansijskih resursa, raspodela rizika na više subjekata radi smanjenja individualnog poslovnog rizika. U tom slučaju neophodno je razvijeno upravljačko računovodstvo kao instrumenat obezbeđenja sigurnosti uloženih sredstava svih učesnika u zajedničkom poslovnom poduhvatu. Drugi slučaj se javlja kada dođe do integracije sa drugim sličnim sistemima i poslovnim interesima što dovodi do stvaranja kompleksne organizacije poslovanja. U ovom slučaju, za ostvarivanje uspešne realizacije takvih ugovora i dugoročnih poslovnih aranžman, neophodan je razvoj primene specifičnog upravljačkog računovodstva. Ostvarivanje namere vlasnika za jačanje kvaliteta upravljanja radi dobijanja međunarodnih sertifikata kvaliteta upravljanja i poslovanja, kao preduslova za uspešniji nastup na širem tržištu i u okruženju, takođe imaju pozitivan odnos prema potrebi razvoja primene specifičnog upravljačkog računovodstva u mikro, malim i srednjim preduzećima u narednom periodu.

\section{KARAKTERISTIKE KLJUČNIH LJUDSKIH RESURSA U MIKRO, MALIM I SREDNJIM PREDUZEĆIMA}

$\mathrm{U}$ istraživanjima ponašanja ključnog osoblja u mikro, malim i srednjim preduzećima prema primeni specifičnog upravljačkog računovodstva, kao značajnog upravljačkog alata za donošenje pravilnih i blagovremenih upravljačkih odluka ispoljavaju se dve karakteristične pojave. Prvo, vla- 
snici i menadžeri imaju pozitivan i veći osećaj potrebe za uvođenje i primenu specifičnog upravljačkog računovodstva, jer uviđaju potrebu za donošenje kvalitetnijih upravljačkih odluka, a posebno u blagovremenom otklanjaju nastalih teškoća u poslovanju zbog uticaja novih brojnih nepovoljnih eksternih uticaja. Drugo, finansijsko i računovodstveno osoblje ispoljava negativan stav prema uvođenju i primeni specifičnog upravljačkog računovodstva. Glavni razlog je nedovoljno poznavanje upravljačkog računovodstva, zatim nedovoljna obučenost u primeni tehnika upravljačkog računovodstva i nedovoljno poznavanje upotrebe informacija za donošenje upravljačkih odluka. Pored toga, nisu dovoljno istraženi razlozi nedovoljne veće pažnje i osećaja za organizovanje naknadne obuke i treninga vlasnika, menadžera, finansijskog osoblja i računovođa za brže ovladavanje primene savremenog upravljačkog računovodstva.

Primetan je nedostatak odgovarajuće literature za reedukaciju vlasnika, menadžera, finansijskog osoblja i računovođa MMSP u primeni modernog upravljačkog računovodstva. Postojeći kadrovi koji poseduju MMSP kao vlasnici ili rade kao menadžeri, računovođe ili finansijski kontrolori su završili više i visoke ekonomske škole i odgovarajuće fakultete, pre mnogo godina, po starim programima sa starim udžbenicima iz upravljačkog računovodstva, koji više nisu aktuelni i upotrebljivi u praksi. Rešenje je u intenzivnijem podsticanju pisanja i objavljivanja nove aktuelne literature iz upravljačkog računovodstva. Obrazovne institucije višeg i visokog ranga, a naročito profesionalne organizacije javnih i ovlašćenih računovođa u narednom periodu će biti mnogo aktivnije $u$ pripremanju, organizovanju i izvođenju treninga uz posao, posebno za vlasnike i menadžere od kojih se očekuje da koriste informacije iz upravljačkog računovodstva, sa jedne strane, da organizuju treninge za računovođe koji će omogućiti brže stručno ovladavanje novim specifičnim metodama i tehnikama upravljačkog računovodstva za MMSP, radi osposobljavanja za brže organizovanje i uvođenje upravljačkog računovodstva u cilju započinjanja "proizvodnje" posebnih upravljačkih informacija neophodnih vlasnicima i menadžerima.

\section{NEKI ORGANIZACIONI ASPEKTI SPECIFIČNOG UPRAVLJAČKOG RAČUNOVODSTVA U MMSP}

U okviru istraživanja koja su u vezi sa ograničenjem i nedostatkom neophodnih resursa u primeni sistema upravljačkog računovodstva ustanovljeno je da je jedan od važnih uzroka smanjenja primene u MMSP, pre svega nedostatak finansijskih sredstava za razvoj ove funkcije u procesu upravljanja, što je uticalo na dugoročan zastoj u razvoju mikro, malih i srednjih preduzeća, u praksi, u prethodnom periodu sa nastankom globalne finansijske krize koja traje od 2008. godine do danas.

Podsticanje razvoja mikro, malih i srednjih preduzeća, naročito u njihovom poslovnom jačanju uz odgovarajuću državnu finansijsku podršku i stimulaciju, radi bržeg podsticanja otvaranja novih radnih mesta, doprineli su i organizacionom jačanju i postepenom potpunom osamostaljivanju funkcije upravljačkog računovodstva. Za razliku od velikih korporacija gde je došlo do potpunog organizacionog razgraničenja između finansijskog i upravljačkog računovodstva, u mikro i malim preduzećima, usled ograničenih finansijskih resursa to je teže ostvarljivo. Međutim u mnogim srednjim preduzećima prisutno je organizaciono razgraničenje finansijskog i upravljačkog računovodstva.

Ograničeni finansijski resursi koji otežavaju ili potpuno onemogućuju organizaciono izdvajanje funkcije upravljačkog računovodstva u posebne organizacione celine mikro, malih i srednjih preduzeća zbog racionalnosti administracije usled postojanja malog obima poslovnih transakcija nije postojala isplativost angažovanja posebnih upravljačkih računovođa. Zbog toga vlasnici MMSP nisu imali interesa ni za organizovanje nezavisnog upravljačkog računovodstva. Međutim, ovaj opravdani ekonomski razlog za neosnivanje posebnog upravljačkog računovodstva uspešno se nadoknađuje ljudskim resursima, u poslednje vreme novim informacionim tehnologijama, nabavkom i instaliranjem kompleksnih računovodstvenih upravljačkih softverskih sistema (ERP, Sun, Scala itd.) koji omogućavaju automatsko formiranje posebnih i nezavisnih baza podataka upravljačkog računovodstva, paralelno sa unošenjem podataka u baze podataka finansijskog računovodstva.

\section{MOGUĆA ORGANIZACIONA REŠENJA SPECIFIČNOG UPRAVLJAČKOG RAČUNOVODSTVA ZA MMSP}

U zavisnosti od veličine organizacije, obima ulaznih računovodstvenih podataka, nabavljenih odgovarajućih računovodstveno upravljačkih i informacionih sistema i konkretnih potreba vlasnika i menadžera za posebnim upravljačkim informacijama, postoje objektivne mogućnosti razvoja posebne organizacione funkcije specifičnog upravljačkog računovodstva u MMSP i to:

a) posebno razvijenu funkciju upravljačkog računovodstva bez upravljačkih računovođa, samo sa posebnim računovodstvenim softverom za vođenje upravljačkog računovodstva i automatsko dobijanje posebnih upravljačkih informacija za vlasnike i menadžere (npr. MM info, Beograd); za mikro i mala preduzeća;

b) posebno organizova funkcija upravljačkog računovodstva sa posebno angažovanim specijalizovanim upravljačkim računovođom u okviru finansijskog računovodstva, i uz primenu razvijenog računovodstvenog, upravljačkog i informacionog softvera (npr. Microsoft Navision), gde je pored automatskog sastavljanja posebnih upravljačkih informacija za potrebe vlasnika i menadžera u srednjim preduzećima, težište angažovanja posebnog upravljačkog računovođe je usmereno na sprovođenje permanentne sistematske interne kontrole (primer kod uslužnih i servisnih organizacija sa velikim prometom skupih rezervnih delova, radi sprečavanja krađa i sličnih potreba;

c) organizovanje posebnog upravljačkog računovodstva, ne samo kao posebne funkcije računovodstva, već i kao posebne organizacione celine sa posebnim ljudskim resursima uz primenu jedinstvenog računovodstveno, upravljačkog informacionog sistema u srednjim i velikim preduzećima sa materijalno robnim poslovanjem, u građevinarstvu, preradi poljoprivrednih proizvoda. U ovom slučaju javljaju se veće potrebe za upravljačkim informacijama (kalkulacije, upravljanje gotovinom, upravljanje zalihama, povećanim obimom internih kontrola naplate potraživanja 
od brojnih posrednika u većem geografskom okruženju, na primer mlekare, pekare, fabrike sladoleda itd.).

Za primere pod (a) i (b) neophodna je veća pažnja i angažovanosti obrazovanih institucija i konsultantskih organizacija u njihovom razvoju i nuđenju većeg asortimana ovog tipa usluga potencijalnim korisnicima iz mikro i malih preduzeća u aktuelnoj praksi.

Za srednja i velika preduzeća situacija je lakša jer postoje mogućnosti korišćenja obilja gotovih rešenja koja primenjuju velike korporacije, a mogu se relativno lako prilagoditi konkretnim potrebama ovog tipa preduzeća u praksi.

\section{0. ČITANJE I RAZUMEVANJE FINANSIJSKIH IZVEŠTAJA OD STRANE VLASNIKA I MENADŽERA MMSP}

Provere i kontrole prilikom izrade i realizacije početnog biznis plana podrazumeva i ovladavanje znanjima i veštinama čitanja finansijskih informacija. Upoznavanje računovodstvenih kategorija i logike omogućuje efikasnu proveru izrađenih projekcija poslovanju sadržanih u početnom biznis planu, posebno poznavanje upoređenja dobijenih rezultata u svom biznis planu sa rezultatima drugih privrednih subjekata, naročito sledećih primarnih finansijskih kategorija:

a) odnosa trajne i kratkoročne imovine, radi izbegavanja preterane imobilizacije sredstava?

b) odnosa dugorocnih i kratkoročnim obaveza, radi ostvarivanja veće finansijske likvidnosti?

c) strukture sopstvenog kapitala, radi jačanja vlasničke glavnice i finansijske pozicije?

d) strukture pozajmljnog kapitala (glavnica, otplata i kamata)?

e) odnosa fiksnih i varijabilnih troškova, radi održavanja racionalne organizacije entiteta?

f) odnosa direktnih i indireknih troškova, radi praćenja ekonomičnosti poslovanja?

g) analize kalkulacija cena koštanja proizvoda ili usluge, radi održavanja konkurentnosti?

h) analize bilansu stanja za odrzavanje finansijske pozicije radnje ili privrednog društva?

i) analize bilansa uspeha - prihoda, rashoda, dobitka ili gubitka (za održavanje rentabilnosti)?

j) analize novčanog toku i upravljanju gotovinom, radi poboljšanja finansijske likvidnosti?

Sticanje sposobnost za brzo i efektno uočavanje promena u poslovanju entiteta, posebno ovladavanje čitanjem pojedinih finansijskih izveštaja i inforamcija, omogućuje uspešno upravljanje poslovanjem i efikasno reagovanje i zaustavljanje eventualnih pojava neuspešnog započetog poslovanja.

\section{LITERATURA}

Damodaran, A. (2007). Korporativne finansije: teorija i praksa (str. 77-79, 96-103, 750-753). Podgorica: MODUS.

Dragojević, D. (2002). Biznis plan: metodologija i primeri. Beograd: Savremena praksa.

Dragojević, D., Đorđević, B., \& Nikitović M. (2000). Preduzetničko računovodstvo. četvrto prošireno izdanje. Beograd: Poslovni biro.

Đuričin, D., \& Janošević, S. (2011). Menadžment i strategija. Beograd: Ekonomki fakultet.

Hartley, W.C.F. (2002). Business Accounting for Managers. (pp. 139-164.). London: Pergamon Press Education.

Horngren, T.C., Datar, M.S., \& Foster, G. (2006). Cost Accounting A Managerial Emphasis (pp. 760-776). New York: Prentice Hall.

Kaplan, R., \& Atkison, A. (1998). Advanced Management Accounting (pp. 298-305). New Jersey: Prentice Hall International Inc.

Lopez-Laviva, O., \& Hiebl Martin, R.W. (2015). Management Accounting in Small and Medium-Sized Enrerprises: $\mathrm{Cu}-$ rent Knowledge and Avenues for Future Research. Journal of Management Research, 27(1), 81-119. doi:10.2308/ jmar-50915

Malinić, D., Milićević, V., \& Stevanović, N. (2015). Upravljačko računovodstvo (str. 3-22; 151-184; 277-340). Beograd: Ekonomski fakultet.

Needles, B.E., Anderson R.H., \& Caldwell C.J. (1991). Financial and Managerial Accounting (pp. 872-892). Boston, Mass: Houghton Mifflin.

Petrović, Z. (2006). Upravljačko računovodstvo (str. 7-9; 171176). Beograd: Univerzitet Singidunum.

Rodić, J., \& Filipović, M. (2010). Računovodstvo troškova i učinaka (str. 70). Beograd: Asimex.

Shi, L., \& Zhang, H. (2011). On Alternative Measurs of Accruals. Accounting Horizons, 25(4), 811-836. doi:10.2308/ acch-50050

Van der Stede, W.A. (2015). Management Accounting: Where from, Where now, Where to? Journal of Management Accounting Research, 27(1), 171-176. doi:10.2308/jmar51059

Zack, G. (2012). Fair Value Accounting Fraud: New Global Risks and Detection Techniques (p. 171). New Jersey: John Wiley \& Sons.

Žarkić-Joksimović, N. (1995). Upravljačko računovodstvo (str. 105-112; 232-240). Beograd: Fakultet organizacionih nauka - Centar za razvoj menadžmenta.

Žarkić-Joksimović, N., Filipović, V., \& Dragojević, D. (1995). Računovodstvo za menadžment, po programu Phare (poglavlje 20). Beogard: Fakultet organizacionih nauka. 


\section{Abstract:}

Upon the outbreak of the global economic crisis in 2008., the management of micro, small and medium-sized enterprises (MSMEs) disposes of insufficient management tools and proper information needed for preparation and proper decision-making process, and all that with the aim to achieve the desirable business outcomes, financial stability and long-term security. The literature in the area of managerial accounting mainly offers solutions designed to meet the needs of large corporations and their management. The management of micro, small and medium-sized enterprises has little in common with the organizations and functioning of managerial accounting intended for large corporations. However, they also require additional managerial information, which is not contained in the contemporary literature. In this paper, the emphasis is placed on development and application of new concepts and tools of managerial accounting which would correspond to the needs of the management of micro, small and medium-sized enterprises. Special features and the need for managerial accounting in micro, small and medium-sized enterprises have long been neglected in the literature and accounting theory worldwide, which has become a limiting factor in their rapid development. This paper presents examples of some key managerial financial information comprising effective business plans, market mobility assessment and expected volume of production or services, necessary budgeting funds, fixed and variable costs, breakpoint profitability for the overall operations of the micro, small and medium-sized enterprises, and cash flow projections. The examples herein presented have already been proven in practice.

\section{Key words:}

specific managerial accounting, management and control, size of the company,

MSME - micro, small and mediumsized enterprises. 